\title{
Control of Respirable Particles in Indoor Air with Portable Negative Air Ion Generator
}

\author{
V. S. Sawant \\ Dept of Physics, Y.C. Institute of Science, Satara, Maharashtra, India. 415001
}

\begin{abstract}
Portable negative air ion generator has been designed and tested. This device generates continuous emission of unipolar (negative) ions and it was evaluated by investigating its ability to remove respirable particles such as different smoke verities (mosquito coil smoke, cigarette smoke, petrol smoke) from indoor air environment. The experiment was carried out in closed glass container, decay rate for particle concentration were obtained in presence and in absence of negative air ions. The particle removal efficiency was obtained and it can be observed that removal efficiency was highest for petrol smoke as compared to cigarette/mosquito coil smoke. The experiment confirms removal of about $95 \%$ respirable particles from indoor air in addition to the natural decay effect.
\end{abstract}

Keywords: Negative Air Ion Generator, Indoor Air, Particle Concentration, Particle Removal Efficiency.

\section{INTRODUCTION}

Combustion of firewood, cigarette, tobacco, mosquito repellent coil, petrol, oil fumes etc leads to air pollution in the form of various gases and smoke particles, which are composed of various chemical components. Smoke contains mainly solid particulates from various pollutant sources. Mosquito coil is made up of camphor, incense, chemicals and some ayurvedic contents with oil base. Although mosquito coil is burnt for mosquito repellent purpose, introduces solid oil based particulates in air and cigarette smoke generated by combustion of the tobacco, generates particulate size ranging from $0.01 \mu \mathrm{m}$ to $4 \mu \mathrm{m}$ (http://www.engineering toolbox.com). Petrol smoke generated by a two stroke engine petrol bike. This smoke consists of various pollutant gases and carbon particles of size up to $2.5 \mu \mathrm{m}$ (http://www. epa.gov/oar/particlepollution/) (http://www. Engineeringtool box.com). Our aim is to find the effect of air ions on these air borne particles.

Removal of the atmospheric pollutants such as suspended particle, pollutant gases such as $\mathrm{CO}, \mathrm{NO}_{\mathrm{x}}$ and Volatile organic compounds is urgent need of the future to control air pollution and Ozone production in troposphere. Ozone in troposphere levels is highly poisonous for plants and animals. The Oxygen ion production using corona discharge is powerful tool for removing effect of above pollutants along with removing suspended biological species.

The particle removing mechanisms by NAI is due to particle charging by emitted ions and electromigration [10], [12], [15]. Several studies have been conducted for particle removing efficiency using ionic cleaners to remove particles from the air [3], [4], [5]. The ion emission has been tested by several investigators for its ability to reduce the indoor aerosol concentration [1], [2], [6]-[9], [11], [13]. Reference [14] reported the effect of negative air ions on fog and smoke.

The laboratory studies are urgently required for using this important tool in open air. In this laboratory experiment the goal of our work is to study the smoke removal efficiency by using negative air ion.

\section{A. Design \& Construction}

\section{Methodology}

Negative air ion generator is developed by using a voltage multiplier circuit. In our system 230 volts $\mathrm{AC}$ is used as input and voltage multiplier configuration of Cockcroft-Walton multiplier is used. The design and photograph is shown in the Fig.1 and Fig.2, it uses more readily available components. While choosing the components precaution is taken to enhance durability, sturdiness and repeatability of the system designed. There are 30 diodes and 30 capacitors used in circuit. A fiber Glass PCB is used for component wiring and high voltage Epoxy/Resin combination is used to avoid shorting of components due to high voltage in the system during any weather condition. A multiple wire shielded cable is used as antenna for ion transmission. In last stage the condenser neon lamp combination is used to regulate the ion emission according to impedance of antenna to ground. This design is noiseless, consumes minimum power of few mill watts for each pulse of ions during operation.

The precaution is taken to put all the diodes with correct polarity. The fiberglass PCB after soldering was washed thoroughly to avoid sparking at high voltages. The pointed pins of diodes and condenser were avoided. The shielded cable wires as antenna is fitted in to nylon rod along with Teflon spacers and nut. These 
shielded wires are positioned in such a way that they almost protrude out from the box into the air. The antenna is soldered to nut which fits on a bolt soldered to component PCB. Thus in transportation the antenna can be separated from main component box. A white wax and high voltage hardener resin/hardener combination is used to protect the circuit in any weather condition. Particularly in humid atmosphere the leakage and sparking is avoided using the above sealing method. The total weight of the ion generator is around 1700 grams.

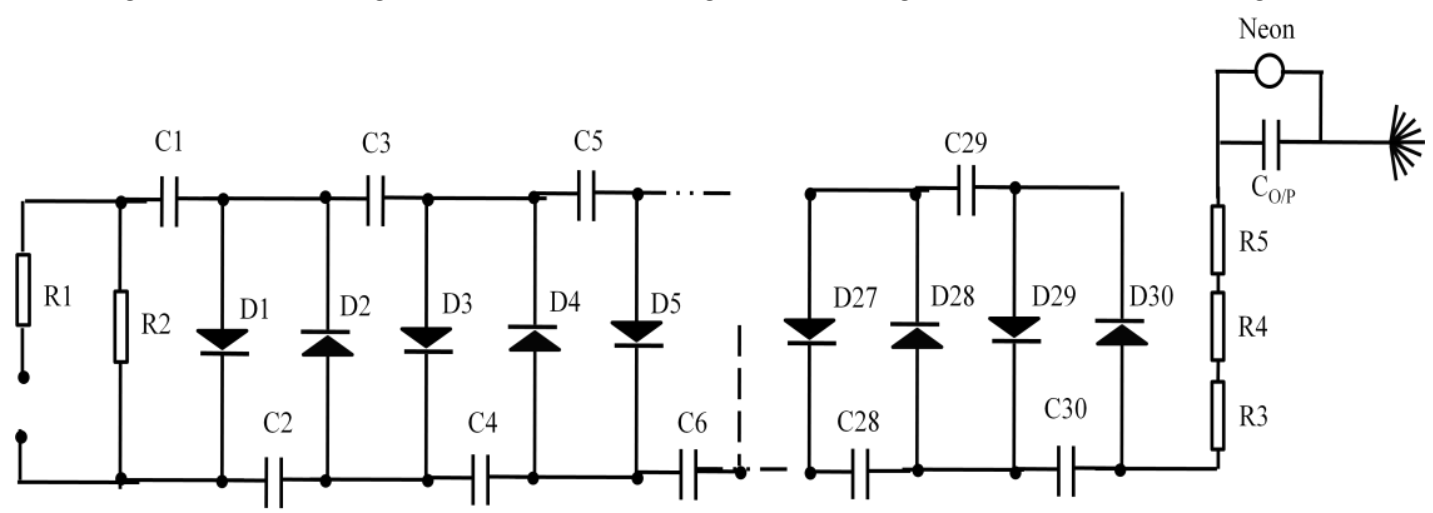

Fig. 1: Schematic of typical air ion generator

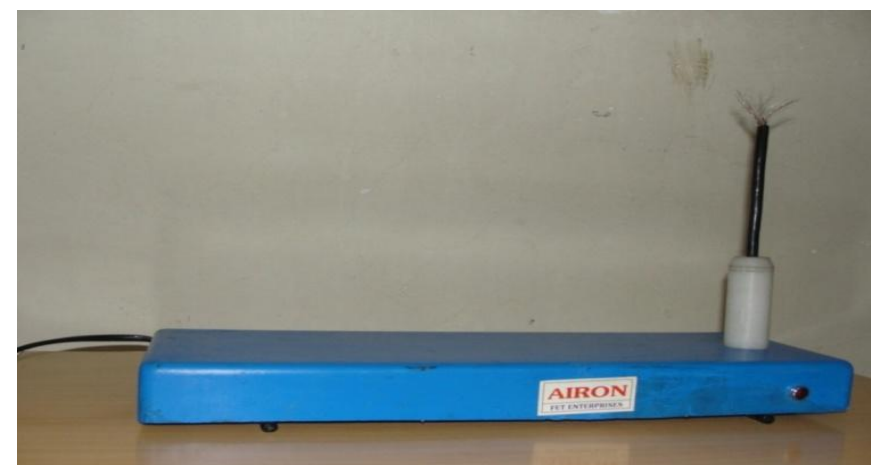

Fig.2 Photograph of Negative Air Ion Generator

\section{B. Experimental procedure}

The experiment was carried out in a dark room. Closed glass container of size $72 \mathrm{~cm}^{3}(\mathrm{~L} \times \mathrm{W} \times \mathrm{H}=$ $60 \mathrm{~cm} \times 30 \mathrm{~cm} \times 40 \mathrm{~cm}$ ) was used. The ion density produced by the device was measured with the help of Air Ion Counter (Alpha Lab Inc., Salt Lake City, UT, USA). This device is capable of measuring within the range of $10^{1}$ $-2 \times 10^{6}$ ions $\mathrm{cm}^{3}$. A Helium-Neon Laser of $2 \mathrm{~mW}, 633 \mathrm{~nm}$ wavelength light source was used. Visibility was measured in terms of light intensity using light meter (lux) model LX - 101A of Lutron. The detector and other electronic equipments were placed at the other end of chamber. Smoke was generated in the glass container. The light emitted by the source enters the experimental chamber filled with smoke. Light intensity was recorded before and after concentration of smoke in the glass container for every 15 second time interval. The ion generator placed inside the container was switched on at minimum light intensity. Fig. 3 shows smoke saturation and decrease in visibility. Fig. 4 shows increase in visibility due to removal of smoke in presence of NAI generator.

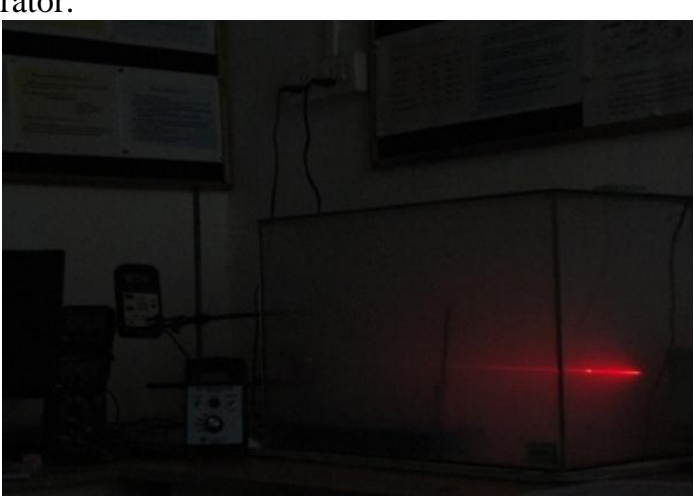

Fig. 3 Smoke saturation

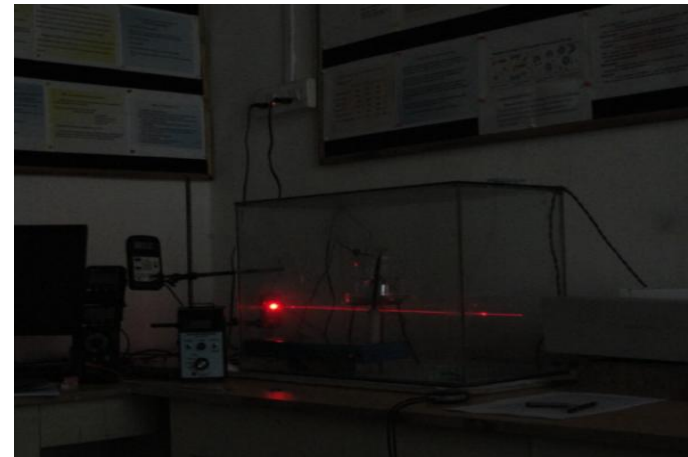

Fig. 4 Smoke dispersion 


\section{Data Analysis}

The natural decay of particle concentration was determined as a base line to test for each particulate matter. Prior to the test, particles of different substrates were generated in the chamber. Then the particle concentration decay with NAI was determined. For each particulate matter $(\mathrm{Pm})$, two concentration decay curves were obtained: the natural decay i.e. when the NAI was 'off" $\left[\mathrm{C}_{\text {Natural }}(\mathrm{Pm}, \mathrm{t})\right]$, and the one with the NAI 'on' [ $\left.\mathrm{C}_{\mathrm{NAI}}(\mathrm{Pm}, \mathrm{t})\right][5][14]$.

The particle removal efficiency was determined as follows

$$
\text { Particle removal efficiency }=\frac{\mathrm{C}_{\text {Natural }}(\mathrm{Pm}, \mathrm{t}=0)-\mathrm{C}_{\mathrm{NAI}}(\mathrm{Pm}, \mathrm{t})}{\mathrm{C}_{\mathrm{Natural}}(\mathrm{Pm}, \mathrm{t}=0)} \times 100 \%
$$

\section{RESULTS AND DISCUSSION}

Particle concentration decay verses time is shown in "Fig.5" with natural decay and NAI application for mosquito coil smoke and petrol smoke. The order of particle concentration decay was natural decay of petrol smoke < natural decay of mosquito coil smoke < mosquito coil smoke decay with NAI application < petrol smoke decay with NAI application. The experimental data proved that the order of particle concentration decay was quite different for all particulate matter. The particle concentration with respect to time shows that the petrol smoke particle concentration reduces fast as compared to other mosquito coil smoke sample.
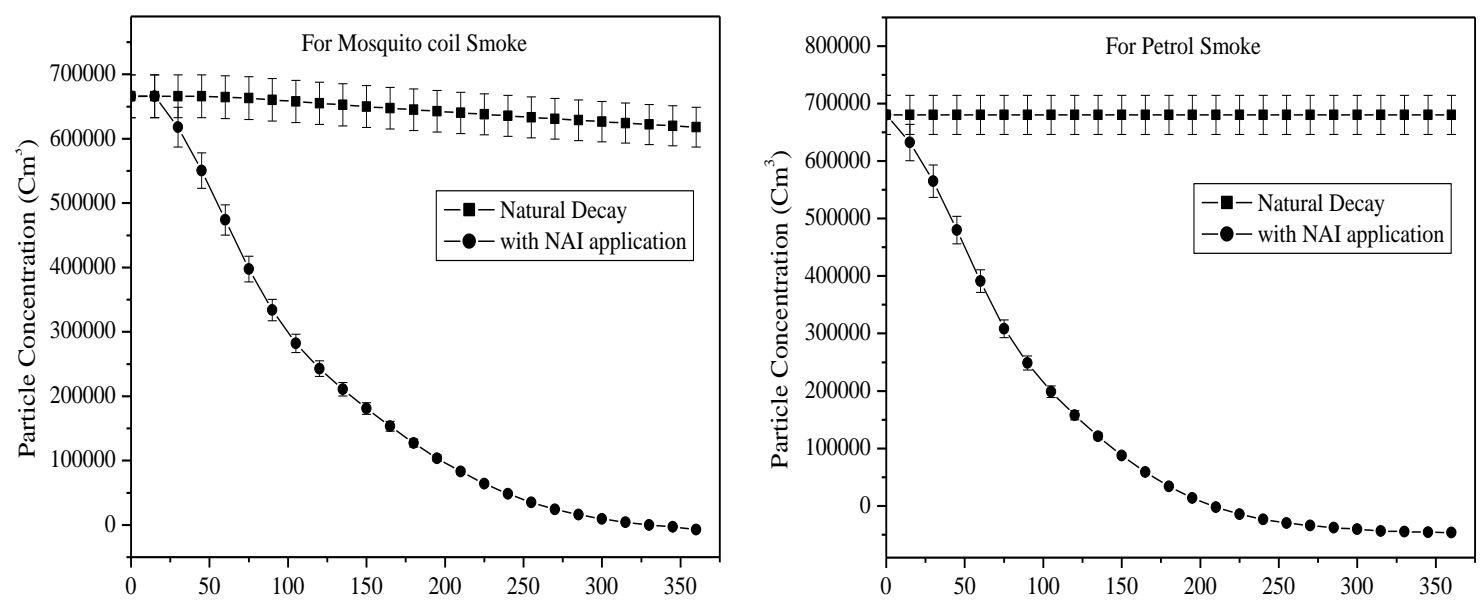

Fig. 5. : Particle concentration decay verses time with natural decay and NAI application for mosquito coil smoke and petrol smoke.

"Fig. 6" shows particle removal efficiency versus time with natural decay and NAI application for mosquito coil smoke and petrol smoke in calm air. The particle removing efficiency is obtained by subtracting the natural decay from the observed value. Mosquito coil smoke natural decay is almost high as compared to natural decay of petrol smoke.
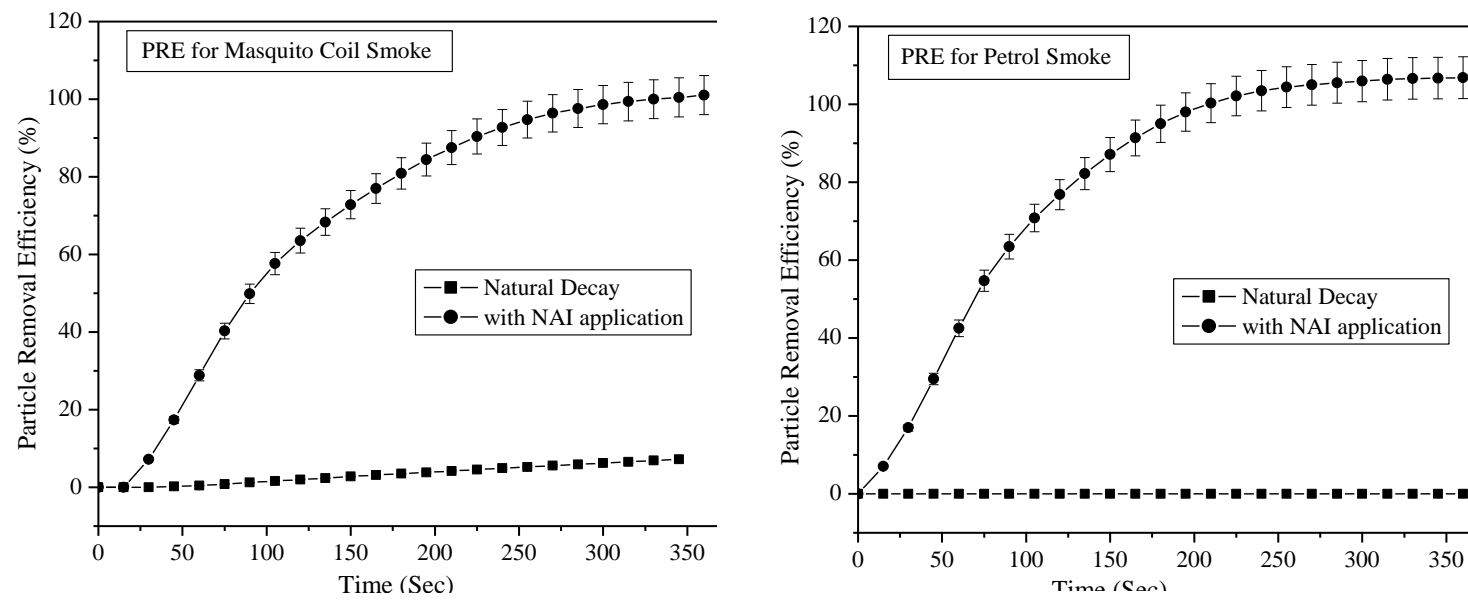

Fig. 6. : Particle removal efficiency verses time with natural decay and NAI application for mosquito coil smoke and petrol smoke. 


\section{CONCLUSION}

In this study, we concluded that the designed Negative Air Ions can remove the aerosol pollutants such as variety of smokes in closed chamber. The particles are charged primarily by the diffusion charging mechanism. The particle removal depends on the ion emission rate. The rate of change of particle removal efficiency is slightly higher for petrol smoke as compared to mosquito coil smoke. This study results that about 95\% respirable particles has been removed from air. In future varying capacity ion generators will become an efficient tool for controlling air pollution.

\section{ACKNOWLEDGEMENT}

Dr. A. S. Burungale, Principal, Y.C. Institute of Science, Satara, for his encouragement and support during this work.

\section{REFERENCES}

[1] Bigu, J. On the e2ects of a negative ion-generator and a mixing fan on the plate-out of radon decay products in a radon box. Health Physics, 1983 , 44(3), 259-266.

[2] Bohgard, M., \& Eklund, P. Effect of an ionizer on sub-micron particles in indoor air. Journal of Aerosol Science, 1998 , 29, S1313S1314.

[3] Grabarczyk, Z. Effectiveness of indoor air cleaning with corona ionizers. Journal of Electrostatics, 2001, 51-52, 278-283.

[4] Grinshpun.S.A.,Mainelis.G.,Reponen.T.,Willeke.K.,Trunov.m.A.and Adhikaty.A. Effect of wearable ionizers on the concentration of respirable airborne particles and Microorganisms. Proceedings of the European Aerosol Conference, Leipzig, germany, j. aerosol Sci., 2001,32 (Suppl. 1), S335-S336.

[5] Grinshpun, S.A., Mainelis, G., Trunov, M., Adhikari, A.,Reponen, T. and Willeke, K. Evaluation of Ionic Air Purifiers for reducing an Aerosol Exposure in Confined Indoor Spaces. Indoor Air , 2005, 15: 235-245.

[6] Harrison, R.G. Ionisers and electrical aerosol removal, Proceedings of $10^{\text {th }}$ Annual Conference, The Aerosol Society, Swansea, UK, 38-40. J. Aerosol Sci., 1996, 27, S191-S192.

[7] Hopke, P. K., Montassier, N., \& Wasiolek, P. Evaluation of the e2ectiveness of several air cleaners for reducing the hazard from indoor radon progeny. Aerosol Science and Technology, 1993, 19, 268-278.

[8] Khan, A., Sapra, B. K., Sawant, V. D., Shaikh, A. N., \& Mayya, Y. S., Behaviour of cigarette smoke in a test enclosure. In Bulletin of Indian aerosol science and technology association, 2000, Vol.13 (pp.160-163).

[9] Kisieliev,N. Cleaning of the Air from the High Disperse Dust by Means of the Artificial Ionization, Moscow, mashinostroienie , 1966 , (in Russian).

[10] Lee, B.U., Yermakov, M. and Grinshpun, S.A. Removal of Fine and Iltrafine Particles from Indoor Air Environments by the Unipolar Ion Emission. Atmos. Environ. 2004, 38: 4815-4823.

[11] Li, C.-S., \& Hopke, P. K. ECcacy of air cleaning systems in controlling indoor radon decay products. Health Physics, 1991, 61, 785797

[12] Mayya. Y.S., Sapra, B.K., Khan, A. and Sunny, F. Aerosol removal by unipolar ionization in indoor environments. J. Aerosol Sci., 2004, 35. 923-941.

[13] Sawant, V.S., Jadhav, D.B., "Laboratory Experiments on Aerosol Removal by Negative Air Ions" in Inter. Conf. on Envir. Science and Technology IPCBEE vol. 30,pp. 63-67, 2012

[14] Sawant, V.S., Meena, G.S. Jadhav, D.B., "Effect of Negative Air Ions on Fog and Smoke" Inter. J. Aerosol and Air Quality Research, $12,1007-1015,2012$.

[15] Wu, C.C., Lee, G.W.M., Cheng, P., Yang, S. and Yu, K.P. Effect of Wall Surface Materials on Deposition of Particles with the Aid of Negative Air Ions. J. Aerosol Sci. 2005, 37: 616-630.

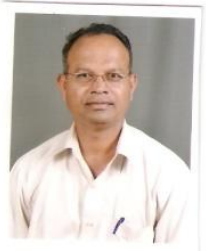

Dr. Vijaysinh Sambhajirao Sawant, Place of birth- Koyananagar, $10^{\text {th }}$ January 1962, Education- M.Sc. (Physics), Ph.D from Department of Physics, University Of Pune, Maharashtra, India. Working Field - Air Ion Generator, Air Pollution, Fog and Smoke Dispersion. Job Title - Associate professor at Department of Physics, Yashvantrao Chavan Institute Of Science, Satara, Maharashtra, India, 415001. He has completed Ph.D. from Indian Institute of Tropical Meteorology Pune, University of Pune, Pune, India. Publications - 1) V.S.Sawant \& D.B.Jadhav, "Laboratory Experiment on Aerosol Removal by Negative Air Ions", in $3^{\text {rd }}$ International conference on environmental Science And TechnologyICEST2012. 2) V.S.Sawant \& D.B. Jadhav, "Effect of Negative Air Ions on Fog and Smoke", in International Journal Aerosol And Air Quality Research, 12, 1007-1015, 2012. 